IZA DP No. 9439

Hurricane Watch:

Battening Down the Effects of the Storm on Local Crop Production

Nekeisha Spencer

Solomon Polachek

October 2015 


\title{
Hurricane Watch: Battening Down the Effects of the Storm on Local Crop Production
}

\author{
Nekeisha Spencer \\ Binghamton University \\ Solomon Polachek \\ Binghamton University \\ and IZA
}

\section{Discussion Paper No. 9439 \\ October 2015}

\author{
IZA \\ P.O. Box 7240 \\ 53072 Bonn \\ Germany \\ Phone: +49-228-3894-0 \\ Fax: +49-228-3894-180 \\ E-mail: iza@iza.org
}

Any opinions expressed here are those of the author(s) and not those of IZA. Research published in this series may include views on policy, but the institute itself takes no institutional policy positions. The IZA research network is committed to the IZA Guiding Principles of Research Integrity.

The Institute for the Study of Labor (IZA) in Bonn is a local and virtual international research center and a place of communication between science, politics and business. IZA is an independent nonprofit organization supported by Deutsche Post Foundation. The center is associated with the University of Bonn and offers a stimulating research environment through its international network, workshops and conferences, data service, project support, research visits and doctoral program. IZA engages in (i) original and internationally competitive research in all fields of labor economics, (ii) development of policy concepts, and (iii) dissemination of research results and concepts to the interested public.

IZA Discussion Papers often represent preliminary work and are circulated to encourage discussion. Citation of such a paper should account for its provisional character. A revised version may be available directly from the author. 


\section{ABSTRACT \\ Hurricane Watch: Battening Down the Effects of the Storm on Local Crop Production*}

This study utilizes a panel fixed effects model to explore the economic impact of hurricanes on local crop production in Jamaica using quarterly 1999-2008 micro level data. We find, in general, that hurricanes will have a negative impact on production but not for crops grown below ground. The exceptions for underground crops being negatively affected are yams and potatoes for which water saturated soil reduces output. From these results, implications are obtained regarding issues such as food security, export expansion, and earnings.

JEL Classification: $\quad$ O13, O54, Q1

Keywords: crop production, exogenous shock, hurricanes

Corresponding author:

Solomon W. Polachek

Department of Economics

State University of New York at Binghamton

Binghamton, NY 13902

USA

E-mail: polachek@binghamton.edu

\footnotetext{
${ }^{*}$ We especially thank Eric Strobl who provided us with data on the hurricane index as well as gave us very useful advice on pursuing the analysis. In addition, we thank Alfonso Flores-Lagunes, Carmen Carrion-Flores and members of the Labor Economics Dissertation Group at Binghamton University for listening and offering their comments throughout the development of the paper.
} 


\section{Introduction}

The Jamaican economy is inherently vulnerable to hurricanes because of its location, its physical size, and it being enclosed by water over which weather disturbances regularly build up. Hurricanes are commonly associated with considerable economic damage despite the country's institutions established to assist in building resilience against these impending disasters. Hurricanes result in loss of lives, damage to infrastructure and agriculture. They also disrupt economic activities and services that are essential to the public.

The focus of this paper is to consider the impact of hurricanes on crop production. The damages to domestic crops, in millions of dollars, done by hurricane Ivan in 2004 and hurricane Dean in 2007 amounts to approximately US\$15 million and US\$13.1 million respectively. These estimates underscore the severity of these disasters. In light of this, the destruction to crops has always been of great concern to the government since it is constantly reevaluating development strategies to increase crop production in order to address issues such as national food security, export expansion, and earnings. Thus, given the country's history of dealing with hurricanes and the government's plans, there is a real need to quantify the effect of hurricanes on crop production. This quantification will help policymakers and workers in the agricultural sector understand the likely impacts before the actual hurricane strikes take place in order to implement mitigation strategies as it relates to planting and to a greater extent organizing resources quickly for reconstruction.

To date, no study has been done on the Jamaican economy as it relates to the impact of hurricanes on crop production. Strobl (2012b) estimates the impact of hurricane strikes on local 
crop production in the Caribbean region. A significant gap in his work is the aggregation of crop production which fails to take account of the fact that some crops are affected differently by hurricanes. Ideally, in trying to establish the link between crop production and hurricanes, one needs to be open to the possibility that there might be varying effects of hurricanes on crops whether they are grown above or below ground. Authors such as Chen and McCarl (2009) establish the importance of investigating these effects on different crops. They find both positive and negative effects on different crops depending on hurricane intensities. This motivated an indepth analysis into various crop groups for Jamaica, which for cyclonic events in Central America and the Caribbean, Hsiang (2010) finds to be negative, as does Strobl (2012b) for the Caribbean. Further, the effects of hurricanes can vary across Caribbean economies depending on the intricacies of the economies themselves and of the hurricanes. Therefore, an analysis of all economies in the aggregate is not sufficient in itself to capture the complete effects of hurricanes on crops in Jamaica.

The innovation in this study is twofold. First, we use micro level data for various crop groups in Jamaica rather than an aggregation of all crops. This allows for a better grasp of the effects of hurricanes on different types of crops and assists in calculating the associated costs of hurricanes. The importance of pinning down the costs is to assess the possible impact before a storm hits, to find out which crops are more resilient to hurricanes and to determine which crops should be the primary focus for the export industry. It is also worthwhile to mention that Strobl (2012b) relied 
solely on 'non-economic data and measures ${ }^{1}$ but here actual crop data are used to assess the effects of the hurricanes. Furthermore, this study paints a picture of how production in a small developing economy is affected by hurricanes. Second, this paper uses a panel fixed effects estimator to investigate the economic impact of hurricanes on local crop production during the period 1999-2008. The construction of the model enables us to carry out an examination of the effects on crop production between sections of the island that are directly affected and those indirectly affected. In general, this study finds that on average, hurricanes reduce crop output, but they do so differently depending on whether crops are cultivated above or below ground. Crops grown above ground have a greater chance of suffering damage than those grown below ground. Specifically, underground crops are not affected with the exception of yams and potatoes for which water saturated soil reduces output. Calculation of hurricane damage shows that the economic losses to the agricultural sector are great. For all the crops considered in this study, losses amount to over US\$120 million for the period of study. Although this study is focused on Jamaica, the approach can be used to analyze shocks to production in other small island developing states in the Caribbean, and elsewhere.

\section{Literature Review}

A large number of studies estimate the impact of natural disasters on output in different countries. Some studies are very broad in that they look at a region or several locations together while others are more specific by looking within countries. Nevertheless, all these studies provide valuable insights that assist in understanding how the behavior of tropical storms or

\footnotetext{
${ }^{1}$ These are estimates of cropland productivity from the Global Land Cover Database which assumes that land is time invariant.
} 
cyclones affect economic output. Dell, Jones, and Olken (2014) find from their research that much attention has been placed on agriculture as it relates to climatic changes. They also point out that many methodological contributions have emerged from this focus. With this in mind, it's worth turning our attention to a few of these studies. From a broader perspective, Strobl (2012a) investigates the impact of hurricane strikes on the growth of GDP per capita in Latin America and the Caribbean. He finds a reduction in output by at least 0.83 percentage points. Like, Strobl (2012a), Hsiang (2010) investigates the impact of temperature and cyclones on output in Central America and the Caribbean. Using multivariate panel regressions with cyclones and temperature as explanatory variables, the results demonstrate that cyclones have both negative and positive impacts on output; however, for the agricultural industry, he finds a negative effect. Similarly, Strobl (2012b) finds a negative and significant effect of hurricanes on crop production in the Caribbean by using a simple fixed effects model. Examining agriculture within a country, Chen and McCarl (2009) use a maximum likelihood estimation approach to estimate the impact of hurricanes on a variety of crops including barley, corn, cotton, potatoes and tomatoes for southern states in America. The impacts varied across crops and states, showing both positive and negative signs. They attribute the difference in signs to the level of rainfall that take place during hurricanes. The study by Chen and Chang (2005) explores how changes in temperature and precipitation affect seven major crops in Taiwan. Maximum likelihood estimation provides mixed results. For example, increasing temperatures and precipitation negatively impact rice, corn and peanut yields. Conversely, higher temperatures increase the outputs of potatoes and soybeans but outputs are decreased by more precipitation. Their results also show that underground crops are able to withstand varying temperatures while those harvested from above 
ground are sensitive to such variations. Like Strobl (2012b), Israel and Briones (2012) examine the macroeconomic impact of typhoons, floods and droughts on agricultural production. The study finds that for the Philippines, these weather events do not significantly impact production at the national level. However, on the provincial level, they show the effect of typhoons on rice production to be negative and significant.

The difference between previous work and the analysis done in this paper is that one is able to isolate the impact of hurricanes on locations that are directly affected by the storm and neighboring locations in close proximity to those experiencing a direct impact. These neighboring parishes experience heavy rainfall and other effects such as storm velocity. Based on information received from the Meteorological Service of Jamaica (MSJ), the hurricanes occurring during the period of study affected the southern parishes on the island slightly more, while the northern parishes, particularly Portland, were less affected. There are also instances in which hurricanes, although directly affecting the southern parishes, affect some northern parishes. Additionally, this suggests that hurricanes affect parishes that are in close proximity to those directly exposed.

One might argue that given the hurricane season and past experience, the agriculture sector should be able to determine when to plant and harvest crops in order to avoid damages by hurricanes. Although there is some expectation that hurricanes can strike between June and November, each hurricane in itself is exogenous since the path, the severity, and potential damage are unpredictable and therefore cannot be taken completely into account. Studies, such as Cameron and Shah (2015) and Callen, Long and Sprenger (2014) indicate changes in behavior based on risk, for example, due to natural disasters and violence. However, the study by 
Campbell and Beckford (2009) indicates this not to be the case in Jamaica. Their analysis examines the case of hurricane Dean with a focus on adaptation and coping strategies of Jamaican farmers. When asked about crop protection prior to the storm, $64 \%$ indicate that they can do nothing to prevent their crops from being destroyed and 73\% report spending more time ensuring the safety of their homes than caring for their crops. A small proportion (2\%) of the farmers uses re-transplanting ${ }^{2}$ method to protect crops. However, Campbell and Beckford (2009) argue that this method can negatively impact growth and development. For almost complete protection, some farmers harvest and store their produce primarily to take advantage of gains from selling at high prices immediately following the passage of a hurricane. ${ }^{3}$ Others contend that premature harvesting reduces the quality of crops. Those who are against pre-harvesting also use the fact that hurricanes often change their path from what is predicted. The latter view supports the earlier point that one is not able to completely determine the course that a hurricane can take. As result, a significant change in the behavior of farmers is unlikely to occur. Their behavior can even be explained by the duration of the storm which is relatively short for Jamaica. Lucas and Rapping (1969) point out that if people believe that a shock might have a short-term impact then they will not change their outlook on its impact in the long run since there is the expectation that the status quo will resume eventually. This long term view is evident in the case study by Campbell and Beckford (2009) where farmers demonstrate their eagerness to rehabilitate their crops in order to reduce losses and focus on growing their crops. It is not

\footnotetext{
${ }^{2}$ This one farmer took his tomato plants in his house and replanted them after the storm.

${ }^{3}$ In our model, we do not account for storage. We have no data on inventories but incorporating the year fixed effects and lags should account for this lack of inclusion although biases could remain.
} 
obvious that farmers in Jamaica undertake precautionary measures that will ensure the safety of crops. Even if any measures are taken, it remains unclear whether they will be successful.

\section{Data}

This paper uses quarterly data on rainfall, crops, land and hurricanes at the parish level for the period 1999-2008. There are 13 parishes. Due to data constraints for crop production, the period of analysis is restricted to 1999-2008. Table 1 below presents the details of the hurricanes. All hurricanes affecting Jamaica during this period are included as per the National Meteorological Service of Jamaica. ${ }^{4}$

Table 1 Characteristics of hurricanes occurring in Jamaica.

\begin{tabular}{llrlc}
\hline Hurricane & Year & Quarter & Wind Speed & Category* \\
\hline Lenny & November, 1999 & 4 & $139 \mathrm{~km} / \mathrm{h}$ & 1 \\
Iris & October, 2001 & 4 & $140 \mathrm{~km} / \mathrm{h}$ & 1 \\
Michelle & November, 2001 & 4 & $140 \mathrm{~km} / \mathrm{h}$ & 1 \\
Charley & August, 2004 & 3 & $120 \mathrm{~km} / \mathrm{h}$ & 1 \\
Ivan & September, 2004 & 3 & $250 \mathrm{~km} / \mathrm{h}$ & 5 \\
Dennis & July, 2005 & 3 & $175 \mathrm{~km} / \mathrm{h}$ & 2 \\
Emily & July, 2005 & 3 & $250 \mathrm{~km} / \mathrm{h}$ & 5 \\
Dean & August, 2007 & 3 & $230 \mathrm{~km} / \mathrm{h}$ & 4 \\
Gustav & August, 2008 & 3 & $119 \mathrm{~km} / \mathrm{h}$ & 1
\end{tabular}

*category based on the Saffir Simpson Scale

Quarterly hurricane wind indices constructed by Strobl (2012b) are also utilized. These indices rely on the Boose, Serrano and Foster (2004) wind field model. Hsiang (2010) also makes use of a wind field model to examine the effect of cyclones in the Caribbean and Central America. The North Atlantic Hurricane database and the National Hurricane Center of the

\footnotetext{
${ }^{4}$ These hurricanes were determined by the Meteorological Service of Jamaica and corroborated with information from the NOAA.
} 
National Oceanic and Atmospheric Administration (NOAA) provide the necessary data to create these indices. The hurricane indices represent a more comprehensive way of estimating hurricane destruction. They take into account the wind speeds and the distance between the eye of the hurricane and each parish. A more detailed description of the hurricane indices is provided in Table 2.

Table 2 Details on the construction of the hurricane index.

The hurricane indexes are constructed in the following way: $H_{i, j, h, t}=\sum_{j=1}^{J} V_{i, j, h, t}^{3} i$ - parish; $j$ - locality within parish $i$; $h$ - hurricane; $t$ - time

This calculates average quarterly destruction per parish.

Hurricane indices are based on the Boose, Serrano and Foster (2004) wind field model which is a version of

Holland's (1980) equation. $\quad V=G F\left[V_{m}-S(1-\sin (T)) \frac{V_{h}}{2}\right]\left[\left(\frac{R_{m}}{R}\right)^{B} \exp \left(1-\left[\frac{R_{m}}{R}\right]^{B}\right)\right]^{\frac{1}{2}}$

\begin{tabular}{l|l|l}
$V_{m}$ : 'maximum sustained wind & $T$ :'clockwise angle that falls & $V_{h}$ : 'forward speed of the
\end{tabular} velocity at any point in the hurricane'

$R_{m}$ - 'radius of the maximum wind between the forward path of the hurricane and a radial line from the hurricane center to the point of interest - parish' speed'. $R$ : 'distance from the center of the hurricane to the parishes'

$G$ : 'wind gust factor'

The wind gust is any unexpected

The radius is the distance between the eye of the hurricane and the point at which the strongest winds occur. As the 'highest winds' increase, it is expected that the radius of these winds will lower. $F$ : 'parameter taking account of any friction occurring at the surface' When the waves of the sea and the hurricane winds interact, friction is created and the waves can actually cause the surface winds of the hurricane to decrease. Hurricanes can produce surface winds ${ }^{5}$ that are destructive and so it is important to take the surface friction factor into consideration when constructing a hurricane index.

$B$ : 'parameter to account for the shape of the wind profile curve' This is related to the hurricane wind asymmetry which results from the forward movement of the storm.
$S$ : 'parameter to take account of the asymmetry due to forward path of the storm'

A hurricane has four quadrants.

There is a higher probability that the strongest hurricane winds are located at the right front quadrant or the right rear quadrant (Xie et al 2011) while the left rear has less wind (Lyons, 2008). Thus, the distribution of wind tends to be uneven in the quadrants. This explains the asymmetry of winds.

\footnotetext{
${ }^{5}$ Surface winds determine the category of a hurricane.
} 
The expected damage of a hurricane at a point of interest is calculated based on:

$H_{i, j, h, t}=\sum_{j=1}^{J} V_{i, j, h, t}^{3} i$ - parish; $j$ - locality within parish $i$; $h$ - hurricane; $t$ - time

This calculates average quarterly destruction per parish for a set of localities when a hurricane strikes.

The Ministry of Agriculture and Fisheries (MAF) maintains a database of crop production (tonnes) for various crops: above ground - cereals, condiments, fruits, legumes, plantains and vegetables; underground crops - other tubers (cassava, coco and dasheen), potatoes and yams. Table 3 displays the statistics for the different crops and Figure 1 shows the percentage of total crop production in each parish. This covers all the crops mentioned above. Data on land area per parish $^{6}$ for each group and rainfall ${ }^{7}$ are also featured in the model. Figure 2 below shows the number of hurricane incidences by parish for the period of study.

\footnotetext{
${ }^{6}$ Land area is measured in hectares.

${ }^{7}$ Rainfall is measured in millimeters (mm). On average, it varies from 303mm to $840 \mathrm{~mm}$ across parishes and $91 \mathrm{~mm}$ to $895 \mathrm{~mm}$ within parishes. Its mean is 432 \& standard deviation is 262.
} 
Table 3 Statistics on Jamaica's crop output.

\begin{tabular}{lll}
\hline Crops & Mean & Std. Dev. \\
\hline Cereals & 36 & 39 \\
Plantains & 374 & 311 \\
Legumes & 109 & 270 \\
Vegetables & 1170 & 1722 \\
Condiments & 359 & 668 \\
Fruits & 377 & 1028 \\
Yams & 2682 & 4100 \\
Potatoes & 381 & 569 \\
Other Tubers & 335 & 446 \\
\hline
\end{tabular}

Figure 1 Percentage of total crop production by parish.

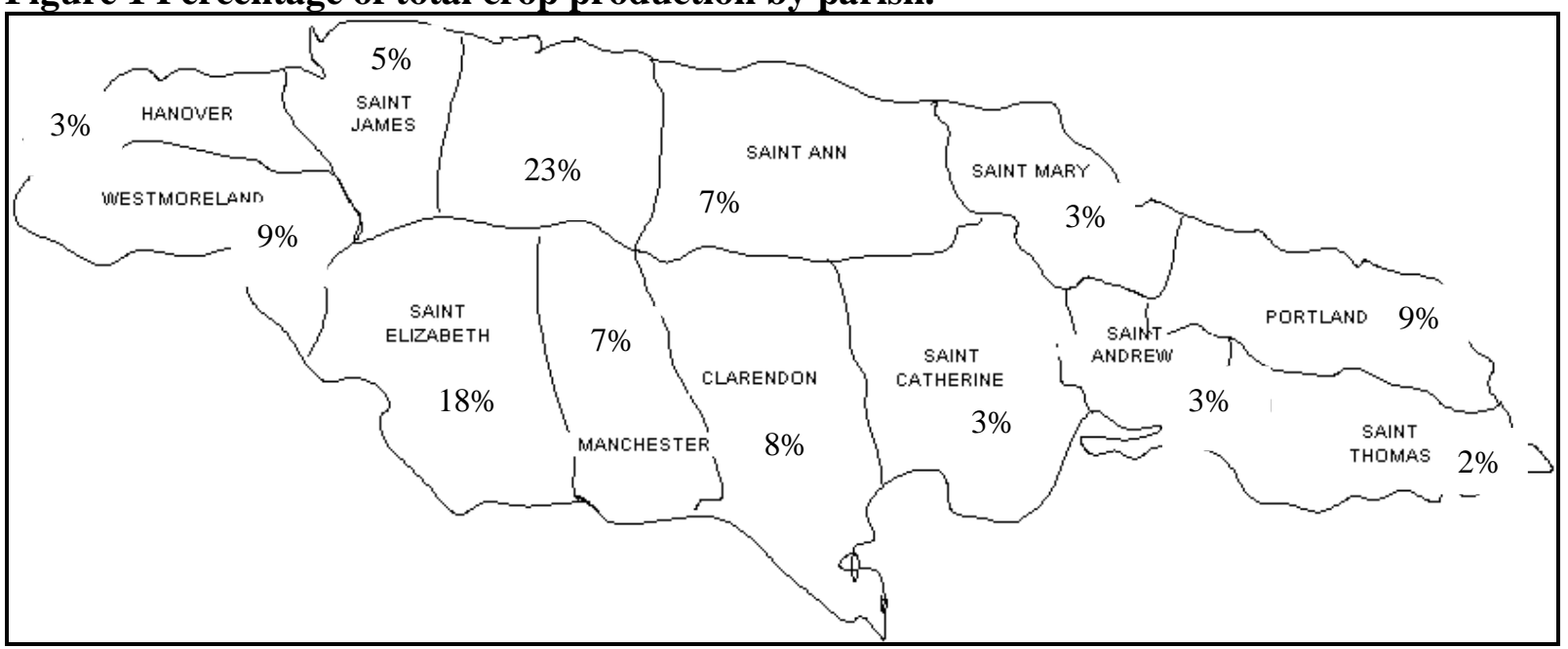

Figure 2 Number of hurricane incidences by parish.

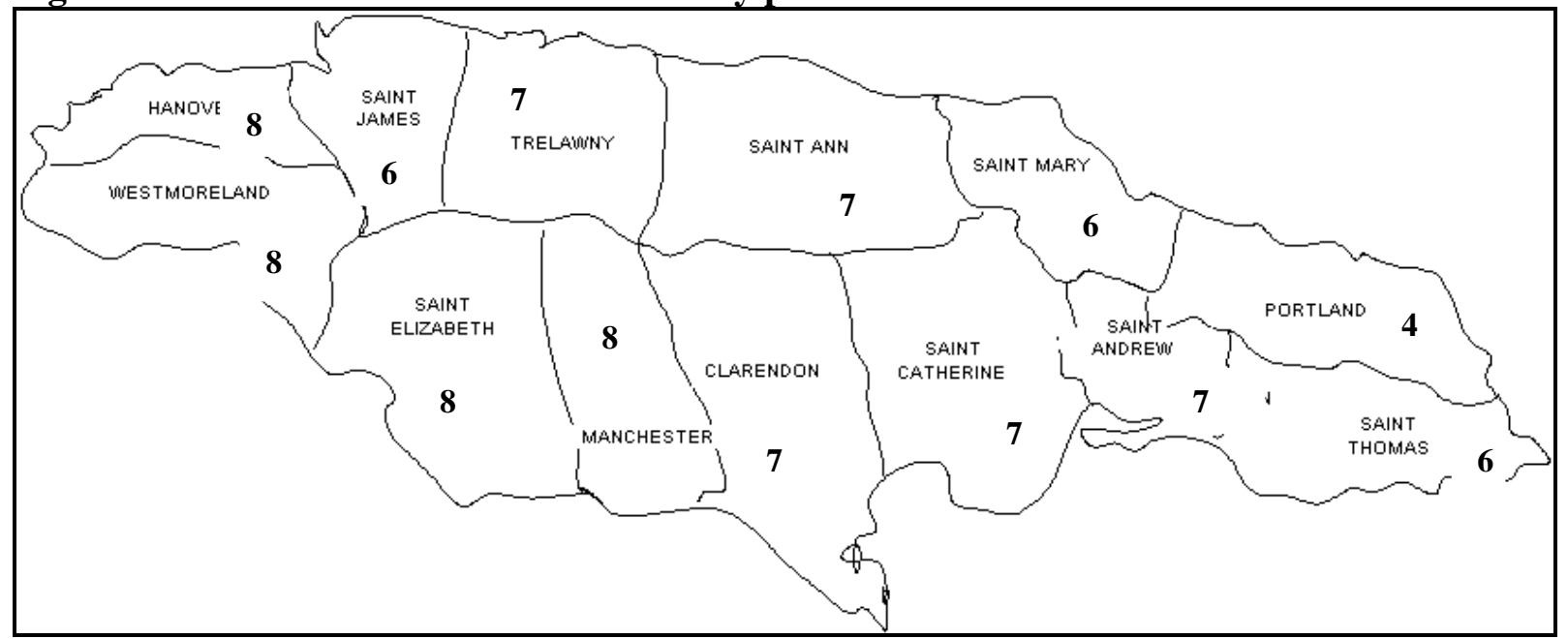




\section{Model Specification}

We use a panel of thirteen parishes and estimate the following equation for three groups of crops $^{8}$ by running a parish fixed effects estimation model. As discussed in section 2, using this estimator controls for the possibility of crop cultivation being a function of the area where a hurricane strikes. Assuming that unobservable location-specific characteristics are time invariant, this approach basically eliminates such unobservables from the equation. ${ }^{9}$

$$
\Delta \ln \left(\frac{C_{i t}}{L_{i t}}\right)=\alpha_{1}+\alpha_{2} R_{i t}+\alpha_{3} H_{i t}^{D}+\alpha_{4} H_{i j t}^{N}+\sum_{p=1}^{4} \alpha_{p}^{D} H_{i t-p}^{D}+\sum_{p=1}^{4} \alpha_{p}^{N} H_{i j t-p}^{N}+\delta_{i}+q_{t}+u_{i t}
$$

Eq. $2^{10}$

$\ln (C / L)$ is the natural logarithm of crop yield per unit of land area by parish. The dependent variable is therefore the percentage change in crop yield per unit of land area between period $t$ (current quarter) and $t-4$ (four quarters earlier) for parish $i$. This lag structure allows for a direct comparison to be made between yields for the same quarters over time. ${ }^{11}$ It thus controls for seasons since crops are usually planted or harvested in the same quarter year after year. $R_{i t}$

\footnotetext{
${ }^{8}$ Aboveground, belowground and water damaged.

${ }^{9}$ The south of the island gets more rainfall on average and more hurricanes. One can argue that this can influence the planting of more crops in the north. However, there has been no evidence to support this. Farmers indicate that the planting of more crops in the northern parishes is due to the land terrain. Our fixed effects model which holds parish unobservables constant takes care of this influence if it exists any at all.

${ }^{10}$ Here rainfall in linear. However, some aspects of the literatures does speak to at least a quadratic form. Including rainfall as a quadratic did not change the results significantly. Even a cubic form did not change the conclusions of the model.

${ }^{11}$ For example, the difference is calculated between: 2002 quarter 2 \& 2001 quarter 2; 2002 quarter 3 \& 2001 quarter 3; 2003 quarter 2 \& 2002 quarter 2 and so on.
} 
captures rainfall. The $H$ variables in the model represent hurricanes. These variables utilize the hurricane indices constructed in equation 1 . Notice that there is not only parish $i$ but also parish $j$; $i$ represents the parishes that are directly affected, and $j$ represents those bordering the directly affected parishes. These latter are referred to as experiencing a neighboring effect. Thus, parishes $i$ and $j$ are located next to each other, and so if a hurricane hits parish $i$, and $j$ borders $i$, then $j$ can experience the effects though indirectly. Thus, $H_{i t}^{D}$ represents a direct hit from a hurricane whereas $H_{i j t}^{N}$ captures the effect on parishes neighboring those directly hit. The Meteorological Service of Jamaica provides data on the sections/parishes of the island most affected by directly hitting and nearby storms. Although Jamaica is a small island, it is mountainous. The mountains run from east to west, north to south forming valleys. Thus, depending on the characteristics of a given hurricane not all parishes will be affected and some may be more affected than others. This has been the case with certain hurricanes where some parishes experienced more destruction than others. Intuitively, there is reason to believe that a hurricane strike affecting production in one parish can have an impact on production in a neighboring parish, especially for hurricanes with wide diameters. As a result, one should determine if there is any real effect on a neighboring parish. When these two effects are isolated, the agricultural sector becomes aware of the likely impacts on production and how to allocate available resources such as materials that farmers might need to restart or continue their lines of production.

We use the data generated from equation 1 to calculate the mean hurricane index for the directly affected parishes and their neighbors to confirm that those directly affected are more 
exposed and did experience harsher effects. To gain some insight into the persistent effects of hurricane strikes, the model also includes lags in the hurricane variables. Lastly, $\delta$ and $q$ are parish and time period fixed effects respectively. The latter are included to hold fixed any peculiarities that might occur in the different seasons; and time fixed effects control for variations for all time periods.

To conclude this section, a few points must be mentioned. A variable for drought is not in the model (MSJ, 2002). According to the MSJ (2012), the island on average has not experienced periods of severe drought conditions. At times, a few parishes fall below normal drought but there has been no noticeable trend for 1999-2008. Finally, data constraints prevent the inclusion of temperature as a control variable in the model. However, Jamaica is a tropical country with temperatures staying rather constant all year. Strobl (2012b) in his paper on Caribbean cropland productivity found temperature to be insignificant. Studies of wider areas such as the entire Caribbean (Hsiang, 2010), the United States (Schlenker and Roberts, 2009) and Sub-Saharan Africa and South Asia (Wood et al., 2014) find temperature to be important, but as mentioned these studies analyze a much wider geographic area than Jamaica, and as such have greater temperature variation. ${ }^{12}$

\section{Diagnostic Tests}

In the literature, spatial dependence is often considered to be a problem in panel data sets. When working with agriculture data sets Lowenberg-DeBoer et al. (2006) point out that spatial autocorrelation can exist in either factors of production or independent variables; for example,

\footnotetext{
12 The MSJ could not provide monthly temperature data by parish for the entire time period. The institution only collects data for specific weather stations and these stations do not exist in every parish across the island. Regrettably, we could not check to see if including temperature would change the results.
} 
topography and characteristics of the soil. Dirienzo et al. (2000) note that data are collected according to location can face the problem of spatial dependence. They also establish that there is a high possibility that crop outputs at distinctive locations are linked if one considers the fact that weather disturbances are highly correlated spatially. In such situations it becomes necessary to use spatial autocorrelation correction methodologies to produce estimates that are not only unbiased but also efficient. The direct gain from such approaches is to enable one to make correct inferences. The fact that the data in this study are location specific indicates that precautionary steps need to be taken with regards to spatial autocorrelation (Dirienzo et al., 2000). Strobl (2012b) also uses Driscoll and Kray’s correction mechanism to take account of spatial correlation among the error terms.

Driscoll and Kray (1998) observe that spatially correlated residuals will have implications for inferences being made from using a dataset that calls for independence among cross-sectional units. Spatial autocorrelation affects the consistency of standard errors and as a result cannot be used to make correct inferences. Consequently, Driscoll and Kray developed a nonparametric covariance matrix estimator that generates standard errors useful for drawing inferences. The primary advantage with this correction technique is that it places no restriction on the form of spatial correlations. Thus, the standard errors are robust across common structures of spatial and temporal dependence. Since, spatial dependence is observed among the parishes, Driscoll and Kray's correction is used to eliminate the possibility of using incorrect standard errors to draw inferences. 


\section{Discussion of Results}

The estimated results are shown in Table 4. Columns 1 to 3 display the results of the model for each crop group. The first column of Table 4 shows the results for crops grown aboveground. Considering this effect, a hurricane reduces production by almost 3.6\% for parishes directly affected while in neighboring parishes there is a reduction by $5.6 \%$. Thus, we are looking at an overall negative impact of approximately $9.2 \%$ which turns out to be statistically insignificant. Observing the lag effects, we notice that the effect on parishes directly affected does get smaller over time and does not persist beyond the second quarter. In contrast, there is no immediate effect on neighboring parishes. It is noteworthy to mention that this effect can include possible effects of farmers altering the specific areas where they plant. However, an informal survey of farmers indicates little changes in location where each crop in planted. In addition, Beckford and Campbell (2009) support this point in their study where only 3 (13.6\%) farmers indicated plans to relocate their farming after a hurricane. A possible explanation for the results shown for crops grown above ground is the fact that farmers are eager to rehabilitate their crops and replant after the storm. Campbell and Beckford (2009) indicate that some farmers engaged in practices to rescue crops and reduce losses. These practices include: mulching, fertilizing and watering which improves the fertility and productivity of the soil, as well as moving farming to a different location. However, the movement of farm plots is to be taken with caution since Campbell and Beckford (2009) indicate only a small number of farmers have this intention. The study does not indicate such movement taking place. Nevertheless, the main reason for this movement is plausible because of the amassing of fertilizers and manure at the bottom of the hill after the storm. In the study, two farmers wanted to take the opportunity of this buildup of nutrients since 
they originally planted on the hillside. These practices and others that are unknown are done on a small scale and can possibly explain the effect on crops that are grown above ground.

The results for crops grown below ground are displayed in column two. Although there are some exceptions (as discussed below), the expectation is that crops grown below ground would not suffer damage due to the passage of a hurricane. As column two shows, in general, there is no negative effect on these crops. This suggests that tubers such as dasheen, coco and cassava are more resilient to the effects of a hurricane strike. Overall, we observe a $22.3 \%$ increase in the growth of these underground crops with neighboring parishes seeing a larger change in output. However, this increase in not significant so we conclude that there is no effect on underground crops.

Column three presents the estimates on crops grown underground that are susceptible to waterlogging. This category of underground crops include yams and potatoes. The estimates show a $37.5 \%$ decline in output for parishes directly affected and a $23 \%$ fall for neighboring parishes. This aggregates to over a $60 \%$ fall in production. One explanation for this negative outcome is that when the soil becomes too saturated with rain, yams tend to absorb excess water causing them to spoil quickly. Furthermore, yams are cultivated all year round with a growth time of 7-10 months (Ministry of Agriculture and Fisheries, 2013). For example, when the yam plant is sown in the first quarter, reaping can take place during the third and fourth quarters. So the crop can mature during the hurricane season when there tends to be a lot of rainfall. In addition, yams are cultivated with 'yam sticks'. These sticks are placed at the area where a yam plant is located so that its vine can grow on the stick. With strong hurricane force winds, the likelihood is high for these sticks to be dragged along with the yam itself. In Campbell and 
Beckford’s (2009) case study, one Jamaican farmer lowered his 'yam sticks’ prior to a hurricane. According to the study, the farmer's approach might increase the likelihood of survival if the yams, as he puts it, 'did not fight in the air'. However, this innovative approach has not been used in the major yam farming areas according to Campbell and Beckford. As a result, it cannot be said that a mitigation strategy was employed for all parishes. In Campbell and Beckford's (2009) report on 'post hurricane harvesting and plant restoration', farmers list sweet potatoes as one of the easiest crop to revive after a hurricane. This confirms the results that potatoes are in fact affected by hurricanes. We also observe that the parishes that are directly affected by hurricanes experience a larger negative effect than their neighbors. Intuitively, this makes sense since their neighbors are not receiving the harsher effects. As previously discussed, in general, parishes directly affected experience more severe effects than their neighbors. Lastly, hurricanes typically bring a lot of rainfall which might explain why rainfall shows a negligible effect on output for all three categories of crops.

The overall effect of hurricanes on output is demonstrated graphically in Figure 3. There we see total crop output from aboveground, underground and water damaged crops as well as how output level in affected. With the exception of underground crops, crops aboveground and water damaged crop outputs show a reduction as is seen on the secondary axis (right axis). 
Table 4 Results estimated from the hurricane-crop model.

\begin{tabular}{|c|c|c|c|}
\hline & Above Ground & Below Ground & Water Damaged \\
\hline \multirow[t]{2}{*}{ Rainfall } & $-.00014 *$ & -.00014 & $-.00019 * *$ \\
\hline & $(.00007)$ & $(.00032)$ & $(.00009)$ \\
\hline \multicolumn{4}{|l|}{ Hurricane Effects } \\
\hline \multirow[t]{2}{*}{ a. Direct } & -.04248 & -.03359 & $-.32999 * * *$ \\
\hline & $(.07608)$ & $(.26775)$ & $(.09682)$ \\
\hline \multirow[t]{2}{*}{ b. Neighboring } & .00395 & .12943 & $-.23119 * * *$ \\
\hline & $(.04248)$ & $(.27862)$ & $(.06521)$ \\
\hline \multicolumn{4}{|c|}{ Lagged Hurricane Effects } \\
\hline \multicolumn{4}{|l|}{$\operatorname{Lag} 1$} \\
\hline \multirow[t]{2}{*}{ a. Direct } & -.01186 & .01778 & -.00005 \\
\hline & $(.00692)$ & $(.02075)$ & $(.00790)$ \\
\hline \multirow[t]{2}{*}{ b. Neighboring } & .00395 & -.16203 & .00988 \\
\hline & $(.00889)$ & $(.23317)$ & $(.01186)$ \\
\hline \multicolumn{4}{|l|}{$\operatorname{Lag} 2$} \\
\hline \multirow[t]{2}{*}{ a. Direct } & -0.00198 & -.07015 & -.05039 \\
\hline & $(.02075)$ & $(.05632)$ & $(.02865)$ \\
\hline \multirow[t]{2}{*}{ b. Neighboring } & $.04051^{*}$ & $.19068 *$ & .00198 \\
\hline & $(.01976)$ & $(.05632)$ & $(.01680)$ \\
\hline \multicolumn{4}{|l|}{$\operatorname{Lag} 3$} \\
\hline \multirow[t]{2}{*}{ a. Direct } & .00988 & -.04644 & $-.02668 * *$ \\
\hline & $(.01778)$ & $(.07509)$ & $(.00988)$ \\
\hline \multirow[t]{2}{*}{ b. Neighboring } & $-.01482 *$ & -.11856 & $-.01877 * * *$ \\
\hline & $(.00790)$ & $(.18871)$ & $(.00296)$ \\
\hline \multicolumn{4}{|l|}{$\operatorname{Lag} 4$} \\
\hline \multirow[t]{2}{*}{ a. Direct } & .01087 & .16796 & .03162 \\
\hline & $(.00988)$ & $(.09880)$ & $(.01976)$ \\
\hline \multirow[t]{2}{*}{ b. Neighboring } & $-.08991 * * *$ & $.15116^{* *}$ & .00790 \\
\hline & $(.02470)$ & $(.05335)$ & $(.04150)$ \\
\hline \multirow[t]{2}{*}{ Total Direct } & -.03557 & .03556 & $-.37549 * * *$ \\
\hline & $(.07644)$ & $(.40615)$ & $(.11211)$ \\
\hline \multirow[t]{2}{*}{ Total Neighboring } & -.05632 & $.19068 * *$ & $-.23020 * * *$ \\
\hline & $(.06756)$ & $(.09586)$ & $(.06599)$ \\
\hline \multirow[t]{2}{*}{ Total Effect } & -.09188 & .22264 & $-.60569 * * *$ \\
\hline & $(.10572)$ & $(.43692)$ & $(.17439)$ \\
\hline Observations; $R^{2}$ & 249;0.2677 & 255;0.2289 & 261;0.3637 \\
\hline
\end{tabular}

$* * *, * *, * ; 1 \%, 5 \%, 10 \%$

Driscoll-Kraay Standard Errors are in parentheses. 
Figure 3 Change in Crop Output over the period: 1999-2008.

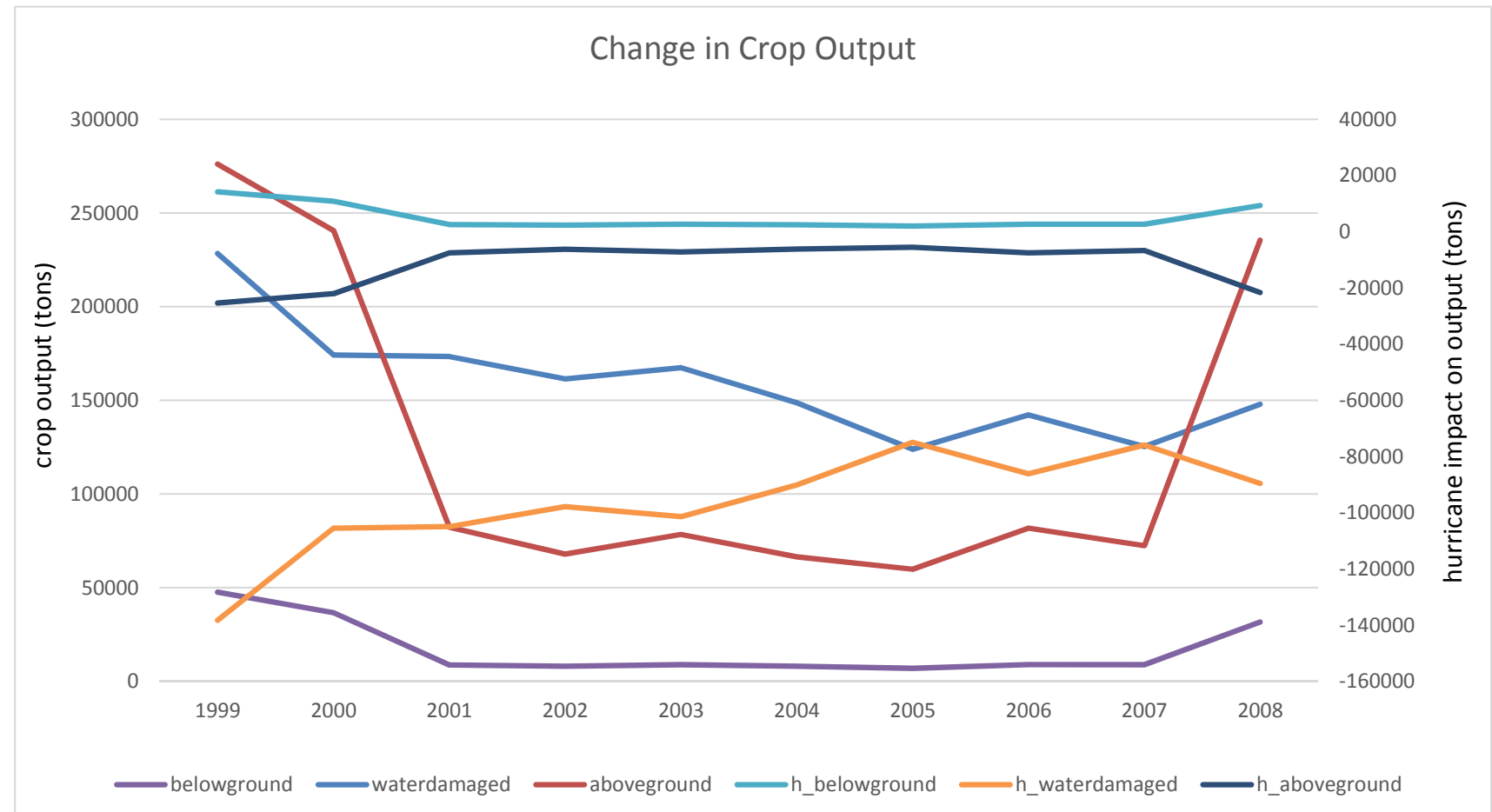

\section{Hurricane Damage Estimates}

The previous section focused on the estimated impact of hurricane strikes. It is also instructive to see what those estimates mean economically for the time period of analysis. Table 5 displays hurricane damage estimates for all the crop groups negatively affected by the hurricanes. Over the period, the country lost over 120 million US dollars in crop revenue due to hurricanes. As the table shows, revenue loss from the underground crops susceptible to water is the higher of the two categories. Of course, the total loss in revenue does not include traditional export crops such as citrus, coco, bananas and sugar which are not covered in this study due to data limitations. These latter agricultural crops always experience even more significant losses. According to an estimate reported by the Planning Institute of Jamaica (2007), these traditional 
crops incurred losses, of approximately US $\$ 90$ million compared to US $\$ 10$ million $^{13}$ for domestic crops from the passage of hurricane Dean in 2007. Clearly, hurricanes do impose severe losses on crop production in Jamaica.

Table 5 Monetary losses in J\$/US\$ for two categories of affected crops.

\begin{tabular}{ll}
\hline Crops & Estimated Loss \\
\hline & \\
Above Ground & $\$ 2,630,000,000$ \\
Underground: Water Damaged & $\$ 6,130,000,000$ \\
Total (J\$M) & $\mathbf{\$ 8 , 7 6 0 , 0 0 0 , 0 0 0}$ \\
Total (US\$M) & $\mathbf{\$ 1 2 0 , 1 3 1 , 6 5 1}$ \\
\hline
\end{tabular}

\section{Conclusion and Policy Implications}

Focusing on sustainable development in the agricultural sector has been a long standing goal for the Jamaican economy. This intent is in an effort to raise levels of production, increase exports and foreign earnings as well as increase the contribution of the sector to GDP. Moreover, the issue of national food security has become a growing concern for many countries and is a prime focus for the Jamaican government. Given these important facts, there is no doubt that there is a great need to pay more than the usual attention to the destruction of crops brought about by hurricanes when designing and implementing strategies to achieve desired outcomes for the economy. This study points to the need for that attention.

\footnotetext{
${ }^{13}$ In 2012 figures.
} 
Our fixed effect panel estimation shows that hurricane strikes reduce the quantity of crops harvested for those grown above ground though the outcome is statistically insignificant. The result for the impact on underground crops is a bit surprising. Underground crops such as yams and potatoes are negatively affected by hurricane strikes. These crops are vulnerable to water saturation of the soil brought about by excessive rainfall due to the passage of hurricanes. This is an unexpected result since one would expect only crops grown above ground to suffer damage. However, there are other underground crops such as cassava, coco and dasheen which are not affected by hurricane strikes.

Our conclusions have implications for other small island economies that are in the Caribbean hurricane belt and engage in crop production. For example, St. Vincent and the Grenadines cultivate similar crops including those susceptible to waterlogging. The results should also be of interest to other territories such as but not limited to Antigua and Barbuda, Dominica, Grenada and Saint Kitts and Nevis. Crop production is a contributing factor to GDP through exports and foreign exchange earnings. Furthermore, the agricultural sectors in these economies remain a means of employment for many. Unfortunately, like Jamaica, these developing economies continue to be vulnerable to adverse weather events such as hurricanes; as a result considering how to shield crop production from adverse effects is no doubt an important consideration for these countries. Campbell and Beckford's (2009) case study did indicate that farmers have been trying to mitigate the effects on their crops. Their coping and adaptation strategies include: re-transplanting ${ }^{14}$; creating roof like structures to lessen the effect from excessive winds and rain; plant bracing and lowering yam sticks; mulching, fertilizing and

\footnotetext{
${ }^{14}$ This one farmer took his tomato plants in his house and replanted them after the storm.
} 
moving farm plot to where soil nutrients accumulate after a hurricane. Although there is no evidence that there has been any large scale implementation of such measures, they are plausible adaptation techniques; thus, the sector can begin looking into a wider application of these mitigation techniques.

Our results also have a direct bearing on exports and national food security. The government of Jamaica can begin assessing the viability of expanding the export basket by including those crops that are more resilient to hurricane attacks such as certain underground crops and those that suffer less destruction from employing adaptation techniques. The results of this study therefore point to a reason for increasing the exports of these crops. As it relates to water damaged crops, Jamaica exports yams which is becoming popular on the export market. Due to the nature of this crop and its vulnerability to hurricanes, attention needs to be given to implementing adaptation techniques; for example, the plant bracing technique employed by one farmer in the Campbell and Beckford (2009) study. Our study also has implications for food security. FAO (2013) mentions that programs addressing food security in Jamaica are not common. This suggests that there is no prioritization of implementing strategies to deal with climatic events such as hurricanes which negatively impact crops and threaten the sustainability of food production. The study by FAO (2013) calls for measures to deal with threats from changes in our climate. Our study supports this viewpoint in that the results point to the destruction and monetary losses from hurricanes. 


\section{References}

Boose E., Serrano, M. and Foster, D. (2004). Landscape and regional impacts of hurricanes in Puerto Rico. Ecological Monograph 74(2): 335-352.

Callen, M., Isaqzadeh, M., Long, J., and Sprenger, C. (2014). Violence and risk preference:

Experimental evidence from Afghanistan. The American Economic Review, 104(1): 123-148.

Cameron L. and Shah M. (2015). Risk-taking behavior in the wake of natural disasters, Journal Human Resources 50 (2), 484-515.

Campbell, D. and Beckford, C. (2009). Negotiating uncertainty: Jamaican small farmers' adaptation and coping strategies, before and after hurricanes - a case study of hurricane Dean. Sustainability 1:1366-1387.

Chen, C. and Chang, C. (2005). The impact of weather on crop yield distribution in Taiwan: some new evidence from panel data models and implications for crop insurance.' Journal of Agricultural Economics 33:503-11.

Chen, C. and McCarl, B. (2009). Hurricanes and possible intensity increases: effects on and reactions from U.S. agriculture. Journal of Agricultural and Applied Economics 41(1): 125-144. Dell, M., Jones, B. and Olken, B. (2014). What do we learn from the weather? The new climate economy literature. Journal of Economic Literature 52(3): 740-798.

Dirienzo, C., Fackler, P. and Goodwin, B. (2000). Modeling spatial dependence and spatial heterogeneity in county yield forecasting models. Paper presented at American Agricultural Economics Association Annual Meeting, Tampa Florida, July 30-August 2.

Driscoll, J. and Kraay, A. (1998). Consistent covariance matrix estimation with spatially dependent panel data. Review of Economics and Statistics 80 (4): 549-560. 
Food and Agriculture Organization of the United Nations (FAO) (2013). Climate change and agriculture in Jamaica: agricultural sector support analysis. Environment and Natural Resources Management Series 21.

Holland, G. (1980). An analytic model of the wind and pressure profiles in hurricanes. Monthly Weather Review 108:1212-1218.

Hsiang, S. (2010). Temperatures and cyclones strongly associated with economic production in the Caribbean and Central America. Proceedings of the National Academy of the United States of America 107(35): 15637-15372.

Israel, D. and Briones, R. (2012). Impacts of natural disasters on agriculture, food security, and natural resources and environment in the Philippines. Philippines Institute of Development Studies Discussion Paper Series No. 2012-36.

Lowenberg-DeBoer, J.M., Griffin, T.W., and Florax, R.J.G.M (2006). Use of cross regression to model local spatial autocorrelation in precision agriculture. Site Specific Management Center, Department of Agricultural Economics, Purdue University.

Lucas, R., and Rapping, L. (1969). Price expectations and the phillips curve. American Economic Review 59(3): 342-50.

Lyons, S. (2008). Why hurricane waves are lopsided. Available online at http://www.weather.com/blog/weather/8_16562.html (accessed September 25, 2012).

Meteorological Service of Jamaica. (2002). Temperature. Available online at http://www.metservice.gov.jm/temperature.asp (accessed August 12, 2012). (2012). Preliminary monthly rainfall summary. Kingston, Jamaica. 
Ministry of Agriculture and Fisheries. (2013). Eat what we grow: choosing plants for the backyard garden. Available online at http://www.moa.gov.jm/EatWhatWeGrow/getting started.php (accessed June 23, 2012). Planning Institute of Jamaica. (2007). Assessment of the socio-economic and environmental impact of hurricane Dean on Jamaica. Kingston, Jamaica.

Schlenker and Roberts (2009). Nonlinear temperature effects indicate severe damages to U.S. crop yields under climate change. Proceedings of the National Academy of Sciences of the United States of America 106(37): 15594-15598.

Strobl, E. (2012a). The economic growth impact of natural disasters in developing countries: evidence from the hurricane strikes in the Caribbean and Latin American region. Journal of Development Economics 97(1): 130-141.

(2012b). The impact of hurricane strikes on local cropland productivity: evidence from the Caribbean. Natural Hazards Review 12(2): 132-138.

Wood, S.A., Jina, A.S., Jain, M., Kristjanson, P., Defries, R.S. (2014). Smallholder farmer cropping decisions related to climate variability across multiple regions. Global Environmental Change 25:163-172.

Xie, L., Liu, H. Liu, B and Bao, S. (2011). A numerical study of the effect of hurricane wind asymmetry on storm surge and inundation. Ocean Modeling 36:71-79. 